\title{
Action in 8 Domains for an 8 Factor Improvement: Infrastructure with Agency
}

\author{
L. Varga ${ }^{a}$
}

\begin{abstract}
Infrastructure with agency" embraces both the physical assets for extraction, production, distribution, and storage of utilities, and infrastructure use for the purpose of trade, business and societal well-being. The micro-level interactions of infrastructure use lead to macro-level structures and patterns which satisfy demand and determine the value of infrastructure to users. Interactions generate and are generated by non-linearities and feedbacks within the various integrated systems and provide a source for exponential growth. This article considers how interactions between Infrastructure, utility businesses, users and consumers, and the government can enable co-evolutionary exponential growth. Eight specific recommendations are made to address an eight factor demand growth. The fruitfulness of these recommendations is impossible to predict because the system is complex, that is evolutionary and adaptive, and depends on future contexts, not least, technologies we cannot imagine today.
\end{abstract}

\section{Introduction}

If we define "critical infrastructure" as "infrastructure with agency" then we embrace both its physical assets for extraction, production, distribution, and storage of utilities ${ }^{1}$ and its use for the purpose of trade, business and societal well-being. 'Infrastructure with agency' highlights the focus of behaviours between infrastructure agents, utility business agents and consumer agents. This is akin to the co-evolution of physical technologies, business designs and social technologies respectively ${ }^{2}$ as described in The Origin of $\mathrm{Wealth}^{3}$. The thesis suggested in this paper is that that the co-evolution of these systems, and the thus the potential for non-linearity and positive feedback, is a key opportunity for exponential growth. 0With three broad groups of agents, co-evolution can occur in six ways: co-evolution within each system, and co-evolution between each system. Opportunities for co-evolutionary change in the context of government give rise to a further three opportunities. These are depicted in Figure 1. The remainder of this paper discusses the prime recommendation for each co-evolutionary relationship.

\section{Infrastructure Coevolution (1)}

A useful conceptualization of the components and structure of any infrastructure system is the conversion points' ontology ${ }^{3}$ which describes assets at any scale. It uniquely defines assets by geographical attributes, but importantly identifies all utility resources consumed by the asset, in the relevant proportions; the resources generated, including waste; the technologies used, and related efficiencies and materials use; and the policies and mechanisms in force, constraining or enabling the adoption of the asset. Interdependencies in a landscape of conversion points can be identified by looking for the presence of conversion

\footnotetext{
${ }^{a}$ Director, Complex Systems Research Centre, Cranfield University, Bedford, UK http://dx.doi.org/10.14453/isngi2013.proc.55
} 
points with similar attributes: 1. the same resources used: identifies resource interdependency, 2. the same policies: identifies governance interdependency, 3. the same technologies: identifies technological interdependency (and potential for technological efficiency improvement), 4. the same geographical coordinates: identifies locational interdependency. Vulnerabilities in the infrastructure can be determined using principles of network theory upon a conversion points' model of the infrastructure.

A way to solve some of the interdependency issues of infrastructure is to create fungible conversion points. Such points can be configured to play a role in one system or another, but may not play both roles simultaneously. For example, batteries in electric vehicles could be used to for electricity grid support ${ }^{4}$ when not providing mobility. This is in contrast to dual roles of infrastructure, such as water reservoirs which deliver flood mitigation and urban water supply concurrently, which create lock-in and compromise the water supplier's ability to trade ${ }^{5}$. In addition, novel uses of the infrastructure, novel combinations of infrastructure assets, new instances of assets, or innovation of new technologies, give rise to potential multi-factor improvements.

Recommendation 1. Use infrastructure for fungible purposes to improve security and resilience.

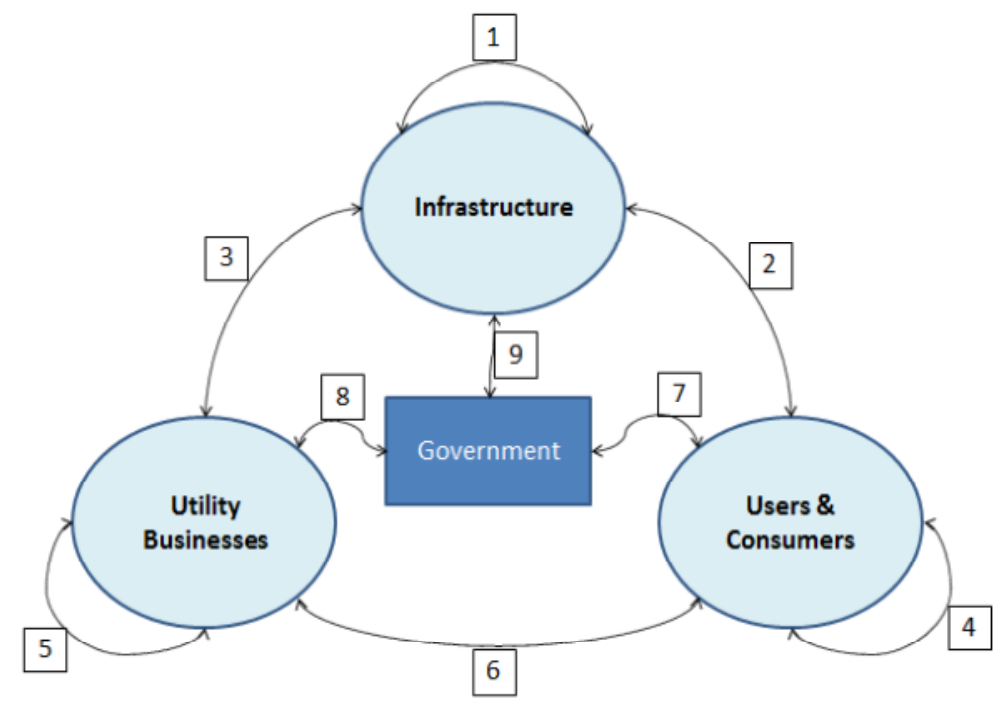

Figure 1 Coevolution of Infrastructure Systems

\section{Coevolution between Infrastructure and Users (2)}

The operational flows of resources, such as water, power, waste, vehicles, and communications, are processed continuously in order to balance supply with demand. But additional physical flows are often available in step changes, for example, another power plant, water treatment works or HGV. At different times there will also be under-utilization of different parts of the infrastructure as well as demand beyond the available capacity. How can utilization be improved? How can losses be avoided? What technologies can be used to improve utilization, for example, how can freight vehicles avoid empty running? What 
technologies are needed to improve efficiencies (and when will they be innovated and tested)?

Recommendation 2: Identify and resolve under-utilization and poor efficiencies, in order to remove avoidable inefficiencies.

\section{Coevolution between Utilities (Businesses) and Infrastructure (3)}

The value of infrastructure is different for different groups and is not reflected accurately in traditional accounting discounted prices, particularly when assets are in use beyond their planned life-times, which is significant for much of the transport and water infrastructure in the UK. A pragmatic approach is to evaluate infrastructure based on the current annual cost of avoiding asset replacement. This approach would need to be pluralistic and take into account the value provided by the system (not just the single asset), the latest technological alternatives for replacement, and the environmental and resource costs of replacement.

Recommendation 3: Assess the value of infrastructure by the costs it avoids in order to improve investment decision making and to reflect pluralistic views and technological alternatives.

\section{User Coevolution (4)}

If users are able and motivated to invest in their own utility generation or works, such as photovoltaic cells, rain-water harvesting, electric vehicles, then as adopters they can acquire skills which can be shared with other users. These users also provide a means of marketing technologies and behaviours for local use usually involving renewable resources. Other users and consumers are influenced by the community networks to which they belong. These practices can avoid demands upon infrastructure and create local security of supply. A recommendation is not made in respect of social networks as they are self-organising.

\section{Utilities (Businesses) Coevolution (5)}

Utilities are focused on single industries, such as power, water, or transport. Whilst usually vertically integrated, they do not collaborate with other utility providers although improvements in one utility can often create greater demand for other utilities which can create worsened systemic effects. Sales are driven by the notion that more is good although the provision of more can lead to step changes in demand provision which are then underutilized and affect consumer prices. A shift in focus to services and not utilities, e.g. not water and energy, but ambient heating/cooling, would create an improvement in understanding the need for more utilities.

This focus on services would require utilities to work differently, for example, through joint ventures at local government level. A multi-utility service perspective would enable regulation to aim at the real benefits of public services. A service perspective would also lead to long term relationships between utilities (and consumers) and create a better focus on 
sustainability. For example, Energy Service Companies (ESCos) implement various energy service business models, which benefit the user through the implementation of energy efficient technologies ${ }^{6}$.

Recommendation 4: Design and create inter-utility solutions service provisions by incentivising inter-utility relations which are beneficial to infrastructure sustainability.

\section{Coevolution between Utilities (Businesses) and Users (6)}

Consumer pricing for utility products needs to reflect utility business costs and the costs of the infrastructure they own or use. Extant consumer pricing strategies are often difficult to fathom and usually encourage excessive use, as the lowest prices are charged for highest consumption. New pricing strategies are needed which encourage limited consumption focused on penalizing excessive consumption. For example, a pricing strategy akin to the tax code system would discourage excess use: there would be a free amount of energy, becoming progressively more expensive.

Recommendation 5: Focus on service need rather than unconstrained demand by actively discouraging excessive use of services.

\section{Coevolution between Users (Consumers) and Infrastructure (7)}

The most significant costs in utilities arise due to oscillations in demand. Flattening demand to make it more predictable will reduce costs. For example, in energy systems, stable demand flattening through smart grid solutions is achievable using smart energy control and communication devices in contrast to traditional methods using wholesale price signals ${ }^{7}$. These methods are new however practical changes are evident globally as we observe domestic, industrial and commercial consumers producing their own utility products and services, such as rain water harvesting, or solar heating, through the use of micro-scale technologies, and sometimes incentivised by government policy. Many small-scale changes will lead to changing demand patterns on national infrastructure. However these solutions will create more oscillations in demand unless technology for storage is innovated at the same speed as renewable energy generation.

Recommendation 6: Make the user and consumer a part of the system and not an exogenous factor by supporting local schemes to capture renewable resources and produce utility products which reduce demand upon aging infrastructure.

\section{Coevolution between Government and Utilities (Businesses) (8)}

Infrastructure needs commissioning, building, operating and decommissioning. Various agencies are involved, including the state for political leadership and regulation, engineering companies, local government for planning and control, materials and resources suppliers, system operators and distribution network operators (for water and energy). The cost of each agency has a bearing on the competence of national infrastructure. How competent is each agency: how effective are its interactions with other agencies? What avoidable barriers are there? Does each agency take appropriate responsibility for security, economics and waste? Is each agency considering integrated improvements in various time dimensions (short, medium 
and long)? The competence of national infrastructure has potential for improvement at various scales: local, municipal, inter-city, and city.

Recommendation 7: Continuously evaluate the competence of national infrastructure in order to resolve inter-agency barriers and to focus on the competence of national infrastructure as a whole system.

\section{Coevolution between government and infrastructure (9)}

It is a very complicated problem to decide which components of infrastructure needs development (and when) for the good of society and the maintenance of GDP. Infrastructure exists at many scales, it may not be located where demand is greatest and it is limited by the technologies used. We can be certain that diversity is needed to provide resilience and opportunities for future pathways, and that the on-going consideration which is needed for prioritization must take into account all utility services. For example, we cannot invest in programmes as significant as HS2 without considering alternatives and parallels such as fast broadband $^{8}$. In the UK's privatised utilities' industry (e.g. the energy industry ${ }^{9}$ ) central government leadership on national projects is a political matter and led by Infrastructure UK, part of HM Treasury who have delivered a long-term plan $^{10}$. The role of the Independent Infrastructure Planning Commission (IPC) in examining applications for "nationally significant infrastructure projects" moved in 2012 to the Planning Inspectorate, an executive agency of the Department for Communities and Local Government (DCLG), following the 2011 Localism Act. However, local and environmental objections to national plans (for example, Channel Tunnel, HS2) appear to be resolved through the creation of hybrid bills which are Acts of Parliament ${ }^{11}$.

The need for balance between local (municipal) and national (or federal) needs is critical to sustainability. Bankruptcies of municipalities in the US (see Detroit's Chapter 9 statement ${ }^{12)}$ are examples of unaffordable debt where local authorities have invested in infrastructure but cannot raise enough revenue (typically through local taxation) to meet repayments and provide on-going quality services. Populations dwindle and the problem becomes intractable. The challenge of investment is the belief that hardship today (high taxes typically) brings rewards (lower cost of services, more services) tomorrow, but individuals' self-interest can wane waiting for the long-term (usually around a generation). Nevertheless free trade and social well-being depend upon infrastructure and so cannot be left to political and thereby short-term decision making. Introducing an apolitical non-governmental body financed by both the Treasury and business, and answerable to social need, is essential for long-term sustainability.

Recommendation 8: Create an interdisciplinary agency to lead national infrastructure strategy thereby creating a long-term plan and benefits realisation programme funded by government and business for the good of the nation.

\section{Conclusion}

A co-evolutionary systems perspective is taken in this paper to identify opportunities to resolve the factor 8 problem in critical infrastructure. The recommendations provided in this paper recognize the significance of agency in these systems and highlight the choices for 
these agencies to change behaviours. Some utilities have specific problems such as the energy 'trilemma' - how to consistently provide affordable energy services, achieve security of energy supplies and reduce greenhouse gas emissions from energy conversions to mitigate climate change ${ }^{13}$ whereas the problems for other utilities are not so clearly defined. The recommendations suggested above reflect the learning gained from a number of critical infrastructure research projects in the last five years. Some recommendations will be fruitful beyond expectations, whereas others may have perverse effects. This is the nature of complex systems in operation. It is only through experimentation that feedback and rebound effects can be observed. In summary, these recommendations are:

- Recommendation 1: Use infrastructure for fungible purposes

- Recommendation 2: Identify and resolve under-utilization and poor efficiencies

- Recommendation 3: Assess the value of infrastructure by the costs it avoids

- Recommendation 4: Design and create inter-utility solutions service provisions

- Recommendation 5: Focus on service need rather than unconstrained demand

- Recommendation 6: Make the user and consumer a part of the system

- Recommendation 7: Continuously evaluate the competence of national infrastructure

- Recommendation 8: Create an interdisciplinary agency to lead national infrastructure strategy

Utility systems are highly dependent on technologies and so I leave the reader with a final thought on the possibilities that technologies hold. Two revolutionary technological daydreams are contained in Arthur C Clarke's afterword in the greatest engineering achievements of the 20th century ${ }^{14}$. The first is a material lighter and stronger than any metal which would enable a space elevator. The second is low-energy nuclear reactions with claims to produce ten times the energy it consumes. With supportive agent behaviours in government, infrastructure, utility businesses and consumers, these technologies alone would go a long way to address the factor 8 issue.

\section{Acknowledgements}

I gratefully acknowledge UK Engineering and Physical Sciences Council (EPSRC) funding as follows: Land of the MUSCos, Grant reference EP/J00555X/1); Transforming Utilities' Conversion Points (TUCP), Grant reference EP/J005649/1; International Centre for Infrastructure Futures (ICIF), Grant reference EP/K012347/1.

\section{References}

${ }^{1}$ HM Treasury, National Infrastructure Plan, HM Treasury, London, 2011, URL: http://cdn.hmtreasury.gov.uk/national_infrastructure_plan291111.pdf

${ }^{2}$ Varga, L., and Grubic, T., "Transforming critical infrastructure", International Innovation, July, 2013, pp. 35-37.

${ }^{3}$ Beinhocker, E.D., The origin of wealth: Evolution, complexity and the radical remaking of economics, Random House, London, 2006.

${ }^{4}$ Tomic, J., and Kempton, W., "Using fleets of electric-drive vehicles for grid support," Journal of Power Sources, Vol. 168, No. 2, 2007, pp. 459-468. http://dx.doi.org/10.1016/j.jpowsour.2007.03.010 
${ }^{5}$ Comisari, P., Feng, L., and Freeman, B., Valuation of water resources and water infrastructure assets, (Australian Bureau of Statistics), United Nations, 2012 URL: http://unstats.un.org/unsd/envaccounting/londongroup/meeting17/LG17_12.pdf

${ }^{6}$ IEA, Task XVI: "Competitive Energy Services", in: Promoting Energy Efficiency and Demand Side Management for global sustainable development and for business opportunities, International Energy Agency (IEA), 2012.

${ }^{7}$ Rylatt, M., Gammon, R., Boait, P., Varga, L., Allen, P., Savill, M, Snape, R., Lemon, M., Ardestani, B., Pakka, V., Fletcher, G., Smith, S., Fan, D., and Strathern,M., "CASCADE: An Agent Based Framework for Modeling The Dynamics of Smart Electricity Systems", Emergence: Complexity \& Organization, Vol. 15, No. 2, 2013, pp. 1-13.

${ }^{8}$ Furguson A., "Why the vision for HS2 and not for broadband?", Think Broadband, 2012, URL: http://www.thinkbroadband.com/news/4962-why-the-vision-for-hs2-and-not-forbroadband.html

${ }^{9}$ Parker, D., The Official History of Privatisation Vol. I: The formative years 1970-1987: v. 1., Routledge, 2009.

${ }^{10}$ Alexander, D., Investing in Britain's future, HM Treasury, 2013, URL: https://www.gov.uk/government/speeches/speech-by-chief-secretary-to-the-treasurydannyalexander-investing-in-britains-future

${ }^{11}$ House of Commons Transport Committee, High Speed Rail: Tenth Report of Session 2010-12, The Stationery Office Ltd., HC 1185-I, 2012, URL: http://www.publications.parliament.uk/pa/cm201012/cmselect/cmtran/1185/1185.pdf

${ }^{12}$ City of Detroit, Chapter 9 Bankruptcy record, 2013, URL: http://www.freep.com/assets/freep/pdf/C4208687718.pdf

${ }^{13}$ Bale, C.S.E., Varga, L., and Foxon, T., "Energy \& Complexity: NewWays Forward", Applied Energy, 2013.

${ }^{14}$ Constable, G., and Somerville, B., A century of innovation: Twenty engineering achievements that transformed our lives. United States: National Academy of Engineering, 2003. 